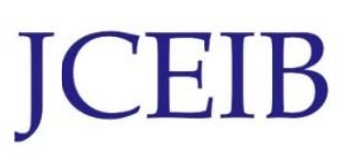

Journal Chemical Engineering and Industrial Biotechnology (JCEIB) Open Access

Volume 4 pp. 19-31; September 2018

CUniversiti Malaysia Pahang Publisher

DOI: https://doi.org/10.15282/JCEIB-V4-02.30/9/2018/4.4

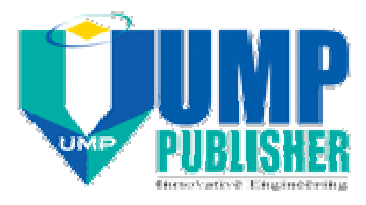

\title{
SUPERCRITICAL WATER GASIFICATION AS A TREATMENT FOR LABORATORY ORGANIC WASTES
}

\author{
Asim Aslam and Farouq Twaiq ${ }^{*}$ \\ School of Chemical Engineering and Science, Swinburne University of Technology Sarawak Campus, \\ 93350 Kuching, Sarawak, Malaysia \\ *Corresponding author: E-mail: ftwaiq@swinburne.edu.my \\ Tel.: +6082269866
}

\begin{abstract}
The thermodynamics of supercritical water gasification (SCWG) was studied in order to determine its potential for treatment of laboratory liquid organic wastes. A thermodynamic model based on the minimization of Gibbs energy was developed in Aspen Plus software that simulated the SCWG of liquid lab organic wastes on an ash free basis. The feed stream contained a mixture of aliphatic (hexane), oxygenated (acetone, ethyl acetate, ethyl ether, isopropyl alcohol and methanol), aromatic (toluene and xylene) and chlorinated hydrocarbons (chloroform and dichloromethane). The model showed that at a pressure of $25 \mathrm{MPa}$, low organic material concentration of 5$10 \%$ in the feed and temperatures over $600^{\circ} \mathrm{C}$, SCWG resulted in hydrogen rich syngas with a trace amount of $\mathrm{HCl}$ in the liquid effluent. High conversion rates were obtained for oxygenated hydrocarbons having destruction and removal efficiency (DRE) greater than $99.99 \%$ with the rest of the compounds having a $100 \%$ DRE. The composition of the gaseous stream was found to be such that the gas could be released safely to the atmosphere or be stored at high pressure. The study established a proof of concept that there is potential for laboratories to use this method to deal with organic lab wastes with the SCWG process effluent that is environmentally friendly.
\end{abstract}

Keywords: Gasification; Gibbs energy; Laboratory organic wastes; Supercritical water.

\subsection{INTRODUCTION}

Various institutions such as hospitals, universities, schools and industrial sites are host to laboratories that perform a wide range of tasks that deal with chemical and biological experimentation. These laboratories can be defined as areas where relatively small quantities of chemicals and other substances are used for the purposes of teaching, research, diagnostic purposes or for any other purpose on a non-production basis (EPA, 2017). These laboratories use a wide variety of chemicals and as such generate a wide range of different chemical wastes, some of which pose hazards to the environment or to human health and safety. As such, to discourage the inappropriate disposal or accumulation of such wastes and to help facilitate the eventual removal of the said wastes, certain protocols are normally set in place. These protocols outline how lab wastes can be categorized, stored and disposed of in a responsible, safe and legal manner. Once the wastes are safely collected and categorized, the disposal process can begin which varies depending on the type of waste being dealt with (Council 1995). For 
this study, the area of concern is on liquid waste streams with high organic content. Such waste streams fall under the category of chemical waste. Some examples of such chemical wastes include but are not limited to chlorinated solvents, aliphatic hydrocarbons, aromatics hydrocarbons, alcohols, glycols, ethers, esters, ketones, aldehydes, amines and amides. Temporary storage of waste is normally done in or near the laboratory. Safety considerations are the primary concerns during storage, therefore, safety protocols dictate that it should be ensured that wastes are classified and stored in separate containers. Wastes are labelled in containers that should be compatible with their contents. There are various regulations that indicate the allowed stored quantities and duration (Fedyaeva \& Vostrikov 2012; Guo et al 2010).

A few methods of waste disposal are currently available. Disposal through the sewer system is appropriate in some cases but it is generally becoming unacceptable in most places (Gasparovic et al 2011). Similarly, the landfill disposal is also becoming a concern due to environmental impacts (Waddell, 2015). The most commonly accepted method of disposal of lab wastes is incineration. For incineration to be effective, the waste should contain at least $60 \%$ combustible material and a moisture content that does not exceed $30 \%$. Under such circumstances, pre-treatment is often required to reduce the moisture content of the waste before it can proceed to incineration process (Kratky \& Jirout, 2015). Incineration is the preferred method of waste disposal due to several reasons. The most important being that it gives the waste generators the best assurance in terms of long term safety from liability as compared to other forms of disposal. Due to the thermal treatment, the associated hazards and volume of the waste are reduced, thus, allowing the residue of the treatment to be disposed of in landfills in a safe and legal manner. However, emissions from waste incineration cannot be eliminated which may emit many hazardous gases such as carbon dioxide, carbon monoxide, sulphur oxide, nitrous oxide, methane, dioxins, fluorinated, perfluorinated hydrocarbons and fine particles are also often present in emissions(Solcov et al 2014). Despite the fact that strict regulations and restrictions are in place to monitor and control these emissions, the concerns about the potential hazards and risks associated with such a process are still very much alive.

The method of accumulating liquid organic waste in laboratories for the purpose of disposal is burdensome and is a potential workplace hazard (Waddell, 2015). As such, there is room for improvement in the status quo and research into much more suitable and environmentally friendly alternative processes and technologies to deal with such wastes are underway. One such technology, which seems to hold promise in this regard, is the process of supercritical water gasification. Many studies done on the topic of supercritical water gasification focus mainly on using it as a means for production of syngas, using moisture rich organic feed such as wet biomass for power generation or waste treatment (Acelas et al 2014; Bircan et al 2012; Byrd et al 2008).

The objective of the current research study was to develop a model that simulated the supercritical water gasification process thatcould represent the liquid organic wastes of laboratories and to determine the products of the SCWG process and whether the reactor effluent could be safely disposed to the environment.

\section{Supercritical Water Gasification}

Supercritical water gasification, which makes use of the special properties of water at its supercritical temperature and pressure $\left(T>374{ }^{\circ} \mathrm{C}\right.$ and $\left.P>22.1 \mathrm{MPa}\right)$, has the ability to convert feedstock with high moisture content into hydrogen rich syngas, without requiring an additional step of pre-treatment of drying the feedstock. It was also noted 
that the process produces little to no char as compared to other traditional gasification processes (Modell, 1977; Chuntanapum \& Matsumura, 2010; Susanti et al., 2014). The supercritical water as a single component fulfils multiple functions in its role as a solvent, reactant and catalyst. These unique thermo-physical properties of water at its supercritical state can be used to break down organic compounds. The mass transfer resistance in supercritical water becomes insignificant due to the fluid's high solubility and diffusivity of gases and organic material. The low di-electric constant of water provides high solvating power for organic compounds. The result is that supercritical water acts as a single phase, non-polar gas with high density but with properties similar to that of organics with low polarity. Add to that the increased concentration of both hydrogen and hydroxide ions due to a higher degree of disassociation at supercritical conditions; the power of the hydrolysis reaction increases as a result. Therefore, while hydrocarbons and gases such as $\mathrm{CO}_{2}, \mathrm{~N}_{2}$ and $\mathrm{O}_{2}$ are highly soluble, inorganic salts remain practically insoluble in supercritical water. This further enhances the oxidation kinetics of the organic species due to the absence of mass transfer limitations under such unique conditions and properties. This is exactly what makes supercritical water compatible and applicable to a wide array of diversified feeds (Youssef, 2011). These properties allow supercritical water to act as a solvent, reactant and catalyst at the same time and create a medium for reaction that is very conductive to the destruction of organic material.

Other advantages include the easy capture and storage of gaseous products utilizing the high pressure reactor conditions. $\mathrm{CO}_{2}$ can also be separated easily from the gaseous product due to its high solubility in water at high pressure (Guo et al., 2010). The selectivity of the process can also be altered by changing the process and reaction conditions. While all these factors give SCWG an edge compared to conventional forms of treatment, taking into account the non-polar behaviour of the fluid reduces the solubility of salts in the water, which lead to salts depositing on the reactor walls alongside plugging problems (Fedyaeva \& Vostrikov, 2012).

\section{Thermodynamic Analysis}

Thermodynamic analysis is a very useful tool to obtain realistic information about the composition of the system when it reaches equilibrium (Withaget al. 2012). The influence of various parameters such as temperature and pressure on the system can be studied independently of the reactor or gasifier design. Each of these parameters can be studied independently in the reactor. Stoichiometric and non-stoichiometric approaches are widely used in the thermodynamics of the equilibrium reactions. The stoichiometric approach is based on the reaction equilibria and their equilibrium state. The contributions on each individual reaction to the system and conversion for each reaction need to be known beforehand (Castello \& Fiori, 2011). A non-stoichiometric method is another approach used to analyse the reaction system (Tushar et al., 2015). In this approach, no reaction stoichiometry need to be defined, only the species in the reaction input and the expected product. The product that enables the system to reach the minimum Gibbs free energy is evaluated and when the minimum Gibbs energy is reached, the energy of reaction will equal zero. The change in Gibbs energy with respect to the extent of the reaction $(\xi)$ is shown in Equation (1):

$$
\Delta_{r} G=\partial G / \partial \xi
$$


If the Gibbs energy of reaction is not zero, then there must be a point of lower Gibbs energy. Thermodynamic models found good predicting for carbon dioxide, hydrogen and methane in biomass gasification of agreement with experimental data (Withag et al., 2012; Tushar et al., 2015). Supercritical water gasification of wet biomass is reported in the temperature range of 500 to $700{ }^{\circ} \mathrm{C}$ and pressures from $23-48 \mathrm{MPa}$. The temperature found to have a significant effect on the yield of product. On the contrary, a change in pressure did not show any significant contribution to the reaction system yield. On other study on the biomass supercritical water gasification syngas and methane yields are increased with lowering the water contents in the feed (Fiori et al. 2012) and high biomass concentration in the feed correspond with lower production of hydrogen (Louw et al. 2014).

The thermodynamic equilibrium model to determine the equilibrium product compositions in the SCWG, with a wide variety of model feedstock compounds is well addressed in the literature (Magdeldin et al., 2016; Louw et al., 2014). The results of these models vary slightly but there are general trends that are in agreement and can be extracted from all these studies. (1) An increase in temperature resulted in an increase in the yield of hydrogen and a decrease in the yield of methane. (2) An increase in the water to biomass feed ratio resulted in an increase in the yield of hydrogen and a decrease in the yield of methane. (3) Increasing the pressure of the system above that of the critical pressure of water did not have any significant effect on the gaseous yields.

The thermodynamic properties of a chemical can be calculated using a properly selected property method. The equation-of-state (EOS) method that can be applied to all phases, while activity co-efficient method is preferred in predicting the properties of polar components. EOS method is recommended when considering high-pressure and high temperature process such as supercritical water conditions (Withag et al 2012). Aspen Plus software hosts a wide range of property methods including the activity coefficient and equation of state methods. For SCWG, an EOS is a more suitable method owing to the high pressure under which the process operates. Fiori et al. (2012) used a Peng-Robinson (PR) equation of state to model the SCWG process and to perform thermodynamic equilibrium calculations. Withag et al. (2012) did a comprehensive review to ascertain which EOS would be most suitable for SCWG. The study noted that while the property method Ideal (based on the ideal gas law) was simple and easy to use, it had difficulties when calculating vapour-liquid equilibrium. This property method also does not consider intermolecular interactions or the volume of the molecules. The study noted that while the Peng-Robinson (PR) and the RedlichKwong (RK) methods did account for intermolecular interactions and the volume of the molecules, they were not very accurate when it came to predicting the fluid behaviour at high pressures. The study noted that these EOS were useful to predict the thermodynamic properties of a pure components but not that accurate for mixture. As such, the study advised to use a mixing rule to better predict the thermodynamic properties of polar mixtures. A mixing rule adds onto the EOS and helps to better predict such thermodynamic properties. The study concluded that a good property method for such chemical processes at supercritical conditions was the Soave RedlichKwong method with the modified Huron-Vidal mixing rule (SRK-MHV2).

The results of a study by Tushar et al. (2015) show that the pressure only had a slight and rather insignificant effect on the equilibrium gas yield. This can be attributed to the thermodynamic model that was used. The fluid package or Equation of State that was used was "IDEAL" on Aspen Plus. In this fluid package, the equilibrium and phase calculations are done mainly using the ideal gas law. The authors used this fluid 
package for the sake of simplicity. It is possible that using such a method does not accurately predict the kinetics and effects of pressure at the supercritical phase. Therefore, the model under-predicts the product gas yield at different pressures. The reason for this claim is that Withag et al. (2012) used a similar thermodynamic model as that of Tushar et al. (2015). The main difference between the two models was that of which fluid package or EOS which was used. Withag et al. (2012) used the EOS of RKS-BM (Redlich-Kwong-Soave with Boston Mathias mixing rule). This predicted the effect of pressure on the SCWG process much more accurately. The ideal EOS does not work accurately at supercritical conditions, as it does not consider the intermolecular interactions and the volume of the molecules themselves. However, the RKS-BM EOS accounts for both of these factors and therefore, is much more accurate. It can be inferred from this that the use of the proper EOS is very important when developing a model that operates at supercritical conditions.

The reason that a non-stoichiometric method was chosen for this study is mainly the fact that the influence of various parameters on the system can be studied without the need to consider the reactor or gasifier design. The method of modelling shows good agreement with experimental studies. The choice of property method or EOS is an important aspect to ensure good accuracy of result. The conclusion reached from the review of established literature and studies is that a cubic form of EOS such as the ones based on Peng-Robinson and Redlich-Kwong-Soave are much more accurate than a simple one based on the Ideal Gas Laws.

\subsection{Model compound selection}

\subsection{MATERIALS AND METHODS}

The model compounds were determined using a survey conducted by Nagasawa et al. (2011). In this survey, various types of solvent and their air-borne vapour concentrations were measured and compared to safety regulations. A total of 47 organic solvents were tested and compared to safety regulations as prescribed by the Ordinance on Prevention of Organic Solvent Poisoning. This regulation categorized organic solvents into three groups, Group 1, Group 2 and Group 3 solvents based on the danger they posed to the humans they were exposed to. Solvents in Group 1 are the most dangerous and those in Group 3 are the least dangerous. Nagasawa et al. (2011) only tested for the 7 Group 1 solvents and 40 Group 2 solvents prescribed in the regulation. 1909 laboratories were surveyed and the results were categorized into five groups in terms of research field. These were agriculture (AGR), biological (BIOL, excluding medicine), medicine (MED), natural science (SCI), and technology and engineering (T\&E). For this study, only the Group 2 solvents were considered. The results of the survey of Group 2 solvents and that those solvents with a normalized percentage of prevalence of more than $10 \%$ were included. This narrowed down the list to 10 compounds as shown in Table 1. These compounds were used in the simulation as a representation of liquid organic lab waste. The property of the selected compounds was obtained from Aspen Plus databank.

\subsection{Product species}

To utilize the Gibbs free energy minimization approach, the species that are expected as the products of the process need to be defined. In the current study, only the organic compounds in the feed were included. The modelling was made based on ash/char free basis. It should also be noted that there are chlorinated hydrocarbons present in the set of chosen model compounds in Table 1. 
Table 1:List of Group 2 Solvents with more than $10 \%$ prevalence. The organic compounds along with the fraction in total waste and the concentration of each respective organic species in $5,15,25$, and $35 \mathrm{wt} \%$ of total organic concentration.

\begin{tabular}{lccccc}
\hline Total Organics Species & NormalizedPrevalence (\%) & \multicolumn{4}{c}{ Organic Feed Concentration $(\mathrm{wt} \%)$} \\
\hline & & 5 & 15 & 25 & 35 \\
Chloroform & 15.86 & 0.79 & 2.38 & 3.97 & 5.55 \\
Acetone & 15.67 & 0.78 & 2.35 & 3.92 & 5.48 \\
Dichloromethane & 4.44 & 0.22 & 0.67 & 1.11 & 1.56 \\
Ethyl acetate & 6.78 & 0.34 & 1.02 & 1.70 & 2.37 \\
Ethyl ether & 7.36 & 0.37 & 1.10 & 1.84 & 2.57 \\
Hexane & 8.01 & 0.40 & 1.20 & 2.00 & 2.80 \\
Isopropyl alcohol & 10.46 & 0.52 & 1.57 & 2.61 & 3.66 \\
Methanol & 18.93 & 0.95 & 2.84 & 4.73 & 6.62 \\
Toluene & 5.63 & 0.28 & 0.84 & 1.41 & 1.97 \\
Xylene & 6.86 & 0.34 & 1.03 & 1.71 & 2.40 \\
\hline Total & 100.00 & 5.00 & 15.00 & 25.00 & 35.00 \\
\hline
\end{tabular}

In a study of the supercritical water gasification of chicken manure by Bircan et al. (2012), the chlorinated species detected in the products was mainly $\mathrm{HCl}$. The presence of dioxins such as polychlorinated dibenzo para dioxins (PCDDs), polychlorinated dibenzofurans (PCDFs), and polychlorinated biphenyls (PCBs) were also tested. PCDDs and PCDFs were not detected but some PCBs were detected. Therefore, 4,4dichlorobiphenyl was also included as a model compound for PCBs that could be formed in the product streams. Some studies also have found the presence of ethane and ethylene in trace amount, therefore, these compounds were included as possible products as well. Under these circumstances, the most important elements and compounds that were included in the product species are water, hydrogen, carbon monoxide, carbon dioxide, methane, ethylene, ethane, hydrogen chloride, chlorine gas, and 4,4-dichlorobiphenyl. The product species in this list are selected based on the assumption that they are the products of the decomposition of organic materials. Organic materials are rich in hydrogen, carbon and oxygen, and decompose into basic compounds of these elements. Methane, ethane, ethylene is included as they are a small chain hydrocarbons and they may form during SCWG. Longer chain hydrocarbons are not included in the list of products as they all assumed to decompose at SCWG reaction condition (Fiori et al, 2012).

\subsection{Modelling and simulation}

The supercritical pressure of water is $22.1 \mathrm{MPa}$. The pressure that the simulation for this study was run at was set at $25 \mathrm{MPa}$. The temperature was ranged from 450 to 700 . And, the feed concentration was varied between $5 \%$ to $35 \%$ organics in feed as shown in Table 1. A thermodynamic equilibrium model, based on a non-stoichiometric approach using the minimization of Gibbs free energy was generated using Aspen Plus software. The RGIBBS reactor module employs calculations based on the Gibbs free energy minimization that can be used to model thermodynamic and chemical equilibrium at a specified temperature and pressure. Under such a set-up, the following assumptions are made:

1. The reactor was considered to be zero-dimensional. 
2. The gasifier was considered to be perfectly insulated so heat losses were neglected.

3. There was perfect mixing and uniform temperature throughout the reactor.

4. Reaction rates were fast and the residence time was sufficient enough so as to allow the system to reach an equilibrium state.

5. The simulation was performed on an ash/char free basis so there was no char production in the process.

Peng-Robinson (PR) was selected as property equation. This property method is accurate in predicting conditions at supercritical states (Louw et al., 2014; Withag et al., 2012). The effluent of the reaction system is analysed in terms of its composition so as to determine whether the chemical composition of the effluent can be disposed of through the municipal drainage system. This is done through the destruction and removal efficiency (DRE) and organic chloride conversion (OCC). The requirements for an incinerator is that the destruction of hazardous waste must achieve a DRE greater than 99.99 percent for each principal organic hazardous constituent (POHC) (Lee et al., 1986). The same standards can be applied to a gasifier as they are both being used to treat the same kind of waste. The Destruction and Removal Efficiency $(D R E)$ is defined in Equation (2) and the Organic Chloride Conversion (OCC) is defined in Equation (3).

Where

$$
\operatorname{DRE}(\%)=\left(\frac{\mathrm{W}_{\text {in }}-\mathrm{W}_{\text {out }}}{\mathrm{W}_{\text {in }}}\right) \times 100
$$

$W_{\text {in }}=$ Mass flow rate of going in $(\mathrm{kg} / \mathrm{h})$

$W_{\text {out }}=$ Mass flow rate of going out $(\mathrm{kg} / \mathrm{h})$

Where

$$
\operatorname{OCC}(\%)=\left(\frac{\mathrm{w}_{\text {in }}-\mathrm{w}_{\text {out }}}{\mathrm{w}_{\text {in }}}\right) \times 100
$$

$W_{\text {in }}=$ Mass flow rate of organic chloride going in $(\mathrm{kg} / \mathrm{h})$

$W_{\text {out }}=$ Mass flow rate of organic chloride going out $(\mathrm{kg} / \mathrm{h})$

\subsection{Model validation}

\subsection{RESULTS AND DISCUSSION}

Results of the model were validated by comparing them with the results in theliterature. By comparing the trend of the effect of temperature on the gaseous species between the model in this study and the model published by Tushar et al. (2015), it could be ascertained whether the base model was working correctly. Regardless of what organic feed is used, thetrend that is seen in experimental studies is similar to the model data at different temperature in which $\mathrm{H}_{2}$ and $\mathrm{CO}_{2}$ yields increases and $\mathrm{CH}_{4}$ and $\mathrm{CO}$ yields decreases (Bryd et al., 2008; Susanti et al., 2012; Nanda et al., 2016). Tushar et al. (2015) used glucose as the feed and the results were in line with the experimental studies. Therefore, as a test run for model validation, the feed was changed to glucose. If the simulation gives results that are in good agreement with Tushar et al. (2015), then the base model is validated with acceptable accuracy. The feed compounds can then be changed to the ones selected as the model compounds for lab waste. It was observed that the gaseous species followed a similar trend. The model has a better correlation at higher temperatures than at lower temperatures. It should be noted that the model used by Tushar et al. (2015) uses ideal gas law for thermodynamic property calculations in which they tend to over-simplify a complex process such as SCWG by ignoring many of the intermolecular interactions, which occur at high pressures. This could over- 
predict the results, which explains the discrepancies between the two models. PengRobinson property method is used in this study, which provides results that are more accurate funder supercritical conditions.

The equilibrium mole fraction of the four gaseous products at different equilibrium temperatures in the range of $450-700{ }^{\circ} \mathrm{C}$ are presented in Table 2 . The root mean square error (RMSE) for the four products are presented in Table 3. The $\% R M S E$ for $\mathrm{CO}$ and $\mathrm{CO}_{2}$ were found within acceptable bounds. The \%RMSE is higher for $\mathrm{H}_{2}$ and $\mathrm{CH}_{4}$. This is because the model that this is being compared with over predicts the results for hydrogen at lower temperatures and under-predicts the results for methane at higher temperatures. Nonetheless, the equilibrium data obtained from the simulation are in good agreement with established models. This base model that was used in this study and by Tushar et al. (2015) are one of the most commonly used models for the SCWG process. It can be concluded that the modelling approach is capable of predicting the product yield with reasonable accuracy.

Table 2: Equilibrium composition (mole fraction) of the gaseous product in the temperature range of $450-700{ }^{\circ} \mathrm{C}$.

\begin{tabular}{lcccccc}
\hline $\begin{array}{l}\text { Product } \\
\text { species }\end{array}$ & 450 & 500 & 550 & 600 & 650 & 700 \\
\hline $\begin{array}{c}\text { Hydrogen } \\
\left(\mathbf{H}_{2}\right)\end{array}$ & 0.2077 & 0.3291 & 0.4413 & 0.5315 & 0.5952 & 0.6330 \\
$\begin{array}{c}\text { Carbon } \\
\text { monoxide } \\
(\mathbf{C O})\end{array}$ & 0.0009 & 0.0020 & 0.0039 & 0.0066 & 0.0101 & 0.0139 \\
$\begin{array}{c}\mathbf{C a r b o n} \\
\text { dioxide }\left(\mathbf{C O}_{2}\right)\end{array}$ & 0.4473 & 0.4161 & 0.3867 & 0.3621 & 0.3435 & 0.3312 \\
Methane $\left(\mathbf{C H}_{4}\right)$ & 0.3439 & 0.2526 & 0.1680 & 0.0996 & 0.0510 & 0.0217 \\
\hline
\end{tabular}

Table 3: The difference (error) $\Delta \mathrm{E}$ and the root mean squared error between the current model and that of reference Tushar et al. (2015).

\begin{tabular}{cccccccccc}
\hline $\begin{array}{c}\text { Product } \\
\text { species }\end{array}$ & $\mathbf{4 5 0}$ & $\mathbf{5 0 0}$ & $\mathbf{5 5 0}$ & $\mathbf{6 0 0}$ & $\mathbf{6 5 0}$ & $\mathbf{7 0 0}$ & $\sum \boldsymbol{E}$ & $\sqrt{ }\left(\sum \boldsymbol{E} / \boldsymbol{n}\right)$ & $\mathbf{1 0 0} \vee\left(\sum \boldsymbol{E} / \boldsymbol{n}\right) / \sum \boldsymbol{E}$ \\
\hline $\begin{array}{c}\text { Hydrogen } \\
\left(\mathbf{H}_{2}\right)\end{array}$ & 0.0180 & 0.0126 & 0.0070 & 0.0031 & 0.0010 & 0.0002 & 0.0419 & 0.0836 & 18.31 \\
$\begin{array}{c}\text { Carbon } \\
\text { monoxide } \\
(\mathbf{C O})\end{array}$ & $2.1 \mathrm{E}-09$ & $2.6 \mathrm{E}-08$ & $1.3 \mathrm{E}-07$ & $4.9 \mathrm{E}-07$ & $1.5 \mathrm{E}-06$ & $3.4 \mathrm{E}-06$ & $5.6 \mathrm{E}-06$ & 0.0010 & 15.45 \\
$\begin{array}{c}\text { Carbon } \\
\text { dioxide } \\
\left(\mathbf{C O} \mathbf{O}_{2}\right)\end{array}$ & 0.0011 & 0.0008 & 0.0004 & 0.0002 & $5.1 \mathrm{E}-05$ & $5.9 \mathrm{E}-06$ & 0.0025 & 0.0207 & 5.42 \\
$\begin{array}{c}\text { Methane(C) } \\
\left.\mathbf{H}_{4}\right)\end{array}$ & 0.0101 & 0.0071 & 0.0039 & 0.0017 & 0.0006 & 0.0001 & 0.0235 & 0.0626 & 40.09 \\
\hline
\end{tabular}

The overall decomposition reaction for such a feed compound in supercritical water is summarized in Equation (4). $\mathrm{CO}$ can subsequently undergo a water-gas-shift (WGS) reaction that may increase yield of the $\mathrm{H}_{2}$ and $\mathrm{CO}_{2}$ gas as shown in Equation (5). $\mathrm{CO}$ and $\mathrm{CO}_{2}$ may also undergo methanation reactions to produce $\mathrm{CH}_{4}$ as shown in Equations (6) and (7). The effect of the oxygen content in a biomass SCWG, with high carbon and low oxygen content, a gas product with a maximum theoretical hydrogen yield is produced (Louw et al., 2014). 


$$
\begin{gathered}
\mathrm{C}_{x} \mathrm{H}_{y} \mathrm{O}_{z}+\mathrm{H}_{2} \mathrm{O} \rightarrow \mathrm{CO}+\mathrm{H}_{2}+\mathrm{CO}_{2}+\mathrm{CH}_{4}+\text { others } \\
\mathrm{CO}+\mathrm{H}_{2} \mathrm{O} \leftrightarrow \mathrm{H}_{2}+\mathrm{CO}_{2} \\
\mathrm{CO}+3 \mathrm{H}_{2} \leftrightarrow \mathrm{CH}_{4}+\mathrm{H}_{2} \mathrm{O} \\
\mathrm{CO}_{2}+4 \mathrm{H}_{2} \leftrightarrow \mathrm{CH}_{4}+2 \mathrm{H}_{2} \mathrm{O}
\end{gathered}
$$

\subsection{Destruction and removal efficiency (DRE)}

The Complete gasification of the aliphatic, aromatic and chlorinated hydrocarbons in the feed was obtained at all the different temperatures and concentrations. The DRE for the oxygenated hydrocarbons (acetone, ethyl acetate, ethyl ether, isopropyl alcohol and methanol) in the feed was above $99.999 \%$ at all the simulated temperatures. This is considered to be near complete gasification of the hazardous feed material. This is in line with the results of multiple studies that have been reported at temperatures above $500{ }^{\circ}$ C. (van Bennekom et al., 2011; May et al., 2010; Schmieder et al., 2000). However, it should be noted that in this simulation, the DRE for oxygenated hydrocarbons decreased slightly with an increase in temperature, which is inconsistent with experimental studies. It should also be noted that the simulation results that were run with a high concentration of organics showed a trend of decreasing DRE with increasing organic concentration in the feed. This trend is in line with the reported results that complete gasification can be achieved even with high organic concentrations of up to $20 \mathrm{wt} \%$ in feed (Susanti et al., 2012). However, the simulation over predicts the DRE at feed concentrations higher than $20 \%$. This could be due to how the Gibbs Reactor operates in the Aspen Plus software as it assumes that equilibrium is reached after an infinite reaction time (Castello et al., 2014). In reality however, this equilibrium is not always reached and this could explain why there is an over-prediction of results as compared to experimental studies.

\subsection{Effect of temperature on product composition}

The effect of temperature of the yields of hydrogen, carbon monoxide, carbon dioxide and methane is presented in Figure 1. Trace amounts of ethylene and ethane were also detected in the simulation results on magnitude of $10^{-6} \mathrm{kmol} / \mathrm{h}$ in the product stream. At such insignificant concentrations, they were not included in Figure 1.The temperature has a prominent effect on the hydrogen and methane yields. It can be noted from Figure 1 that with increasing temperature, the hydrogen yield increased and the methane yield decreased. The water gas shift reaction, which is endothermic, is favoured at high temperatures and the methanation reaction, which is an exothermic reaction, is favoured at relatively lower temperatures. The theory and experimental studies suggest that with increasing temperature, an increase in carbon dioxide alongside a slight increase and carbon monoxide is expected so as to compensate for the methane consumption (van Bennekom et al., 2011). The small increase in CO can be observed in Figure 1. However, the model in this study shows that an increase in temperature resulted in a slight decrease in the production of carbon dioxide. Tushar et al. (2015) and Withag et al. (2012) reported similar simulation results. Nevertheless, this small inconsistency does not affect the overall accuracy of the results as the trends are still within good agreement with experimental studies (Byrd et al., 2008; Castello et al., 2014; van Bennekom et al., 2011). 


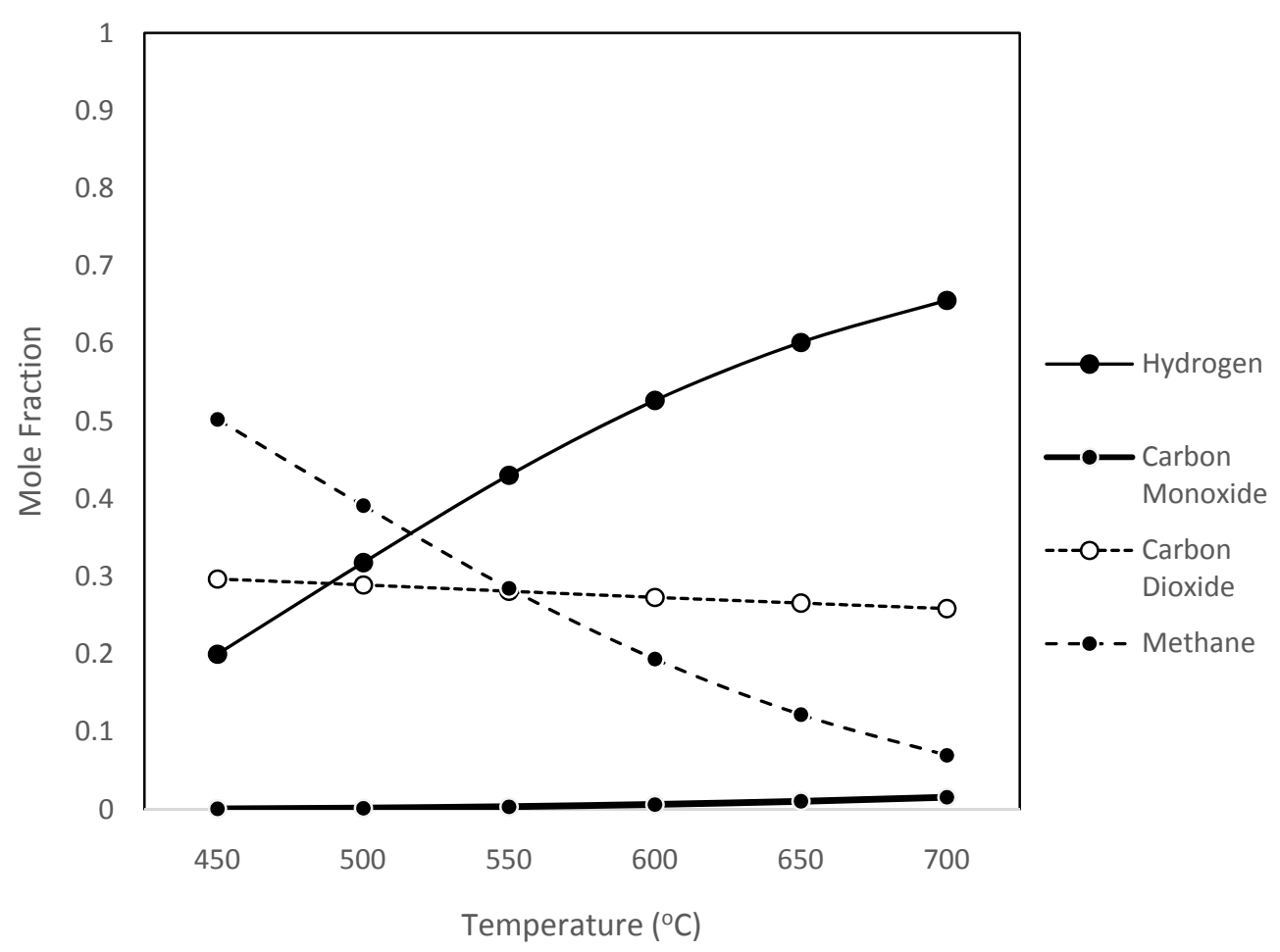

Figure 1: The effect of temperature on the product gas species (dry gas basis)

\subsection{Effect of feed organic concentration}

The concentration of the organic material in the feed also has a prominent effect on the hydrogen and methane yields. The water gas shift reaction, which is endothermic, is favoured at high temperatures and the methanation reaction, which is an exothermic reaction, is favoured at relatively lower temperatures. This is confirmed from Figure 2 which shows that with increasing organic concentration in the feed, the hydrogen yield decreases and the methane yield increases. Similar trends from simulations were observed in a study by Withag et al. (2011) and Tushar et al. (2015), and in experimental studies by Susanti et al. (2014) and Bennekom et al. (2011). Trace amounts of ethylene and ethane were also detected in the product stream. The largest amounts of ethane and ethylene were detected at the $35 \%$ organic feed concentration on a magnitude of $10^{-3}$ and $10^{-5} \mathrm{kmol} / \mathrm{h}$, respectively. At such insignificant concentrations, they were not included in Figure 2.

\subsection{Organic chloride conversion (OCC)}

The organic chloride conversion (OCC) is found to be $100 \%$. At all temperatures above $450{ }^{\circ} \mathrm{C}$ with a $5 \%$ organic material in the feed, the PCB concentration $(4,4-$ dichlorobiphenyl) was found to be zero. It can be inferred that at higher temperatures, the destruction of intermediate compounds, which form such PCBs, is much more thorough. The results, as shown in Table 4, also show that at feed concentrations higher than $5 \%$, some PCBs are produced. These are in the range of $10^{-46}$ to $10^{-39} \mathrm{kmol} / \mathrm{h}$. The trend is such that the higher the feed concentration, the higher the concentration of PCBs that are produced. These results are in agreement with experimental studies by Bircan et al. (2012) which also concluded that at higher temperatures and lower concentrations, the concentrations of PCBs produced are lower. 


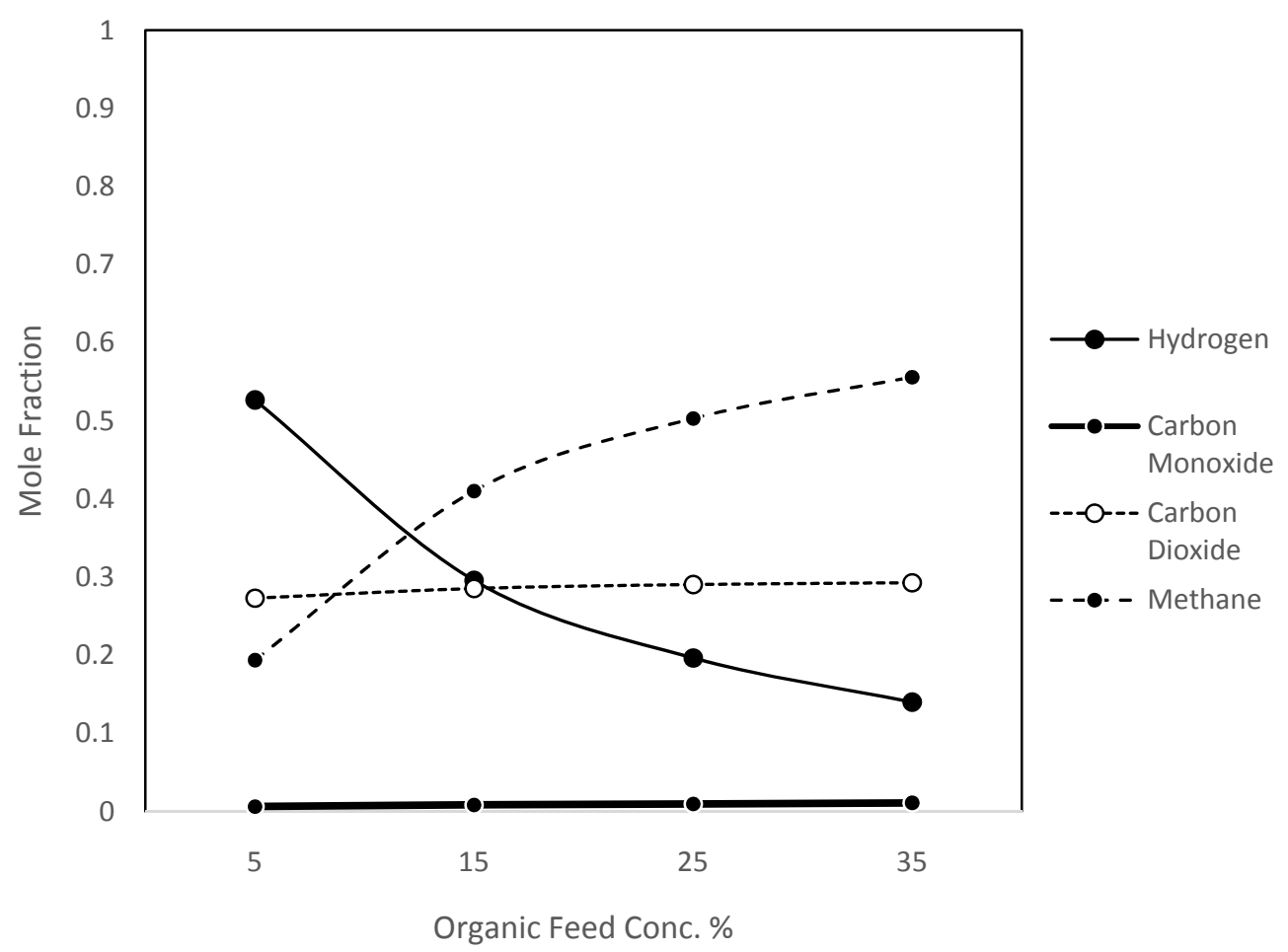

Figure 2: Effect of organic feed concentration on the product species (dry gas basis)

Table 4: The molar flow rate and mole fraction of PCBs in the product liquid stream

\begin{tabular}{lcccc}
\hline Organics Feed Conc. (\%) & 5 & 15 & 25 & 35 \\
\hline PCB (kmol/h) & 0 & $9.15 \mathrm{E}-46$ & $5.06 \mathrm{E}-42$ & $3.10 \mathrm{E}-39$ \\
PCB (Mole Frac.) & 0 & $2.1 \mathrm{E}-46$ & $1.3 \mathrm{E}-42$ & $9.7 \mathrm{E}-40$ \\
\hline
\end{tabular}

The results from the simulation indicate that there was a complete conversion of organic chloride at all different temperature and concentrations. Studies show that there is virtually no $\mathrm{Cl}_{2}$ gas produced during SCWG process (Fedyaeva \& Vostrikov, 2011). In reality, this $\mathrm{Cl}_{2}$ will become $\mathrm{HCl}$ when it comes into contact with water. The reason this simulation shows the production of $\mathrm{Cl}_{2}$ is the fluid package that was used to simulate the process at supercritical conditions. This fluid package that gives relatively accurate results for processes operating at supercritical conditions is not so accurate when it comes to the prediction of the production of ionic species. Another fluid package is needed to accurately determine the ionic and dissociative activities of compounds such as $\mathrm{HCl}$ and $\mathrm{Cl}_{2}$ in water. Unfortunately, these two fluid packages cannot operate side by side in the same model due to the limitations of the modelling software. Overall, the results are still in agreement with studies by Bircan et al. (2012) and Fedyaeva and Vostrikov (2011).

\subsection{CONCLUSIONS}

High destruction and removal efficiency (DRE) was observed at all temperatures with low concentrations of organics in the feed in 5-10\% range. A one hundred per cent organic chloride conversion (OCC) were obtained at all temperatures and feed concentrations. The formation of PCBs was found to be suppressed at high temperatures with low organic feed concentrations $5-10 \%$. Within the context of the obtained results, 
the proposedoperating parameters to achieve a $99.99 \% D R E$ are at anorganic feed concentration of $5-10 \%$ and a temperature above $600{ }^{\circ} \mathrm{C}$. The liquid effluent was found to be water with traces of $\mathrm{HCl}$, which could then be safely disposed of through the municipal drainage system. Therefore, the study established a proof of concept that supercritical water gasification (SCWG) process can be applied for the destruction and treatment of liquid lab organic wastesin order to reduce the waste toxicity and aid with disposal through themunicipal drainage system.

\section{REFERENCES}

Acelas N, Lopez D, Brilman DW, Kersten SR, Kootstra AM (2014). Supercritical water gasification of sewage sludge: Gas production and phosphorus recovery. Bioresource Technology, 174:167-175. DOI:10.1016/j.biortech.2014.10.003

Bircan S, Matsumoto K and Kitagaw K (2012). Environmental Impacts of Hydrogen Production by Hydrothermal Gasification of a Real Biowaste. Gasification for Practical Applications. InTech. pp 211 - 224. http://dx.doi.org/10.5772/50329

Byrd A, Pant K and Gupta R (2008). Hydrogen production from glycerol by reforming in supercritical water over $\mathrm{Ru} / \mathrm{Al}_{2} \mathrm{O}_{3}$ catalyst. Energy Fuels, 87(13-14):29562960. DOI:10.1021/ef700269z.

Castello D and Fiori L (2011). Supercritical water gasification of biomass: Thermodynamic constraints. Bioresource Technology, 102(16):7574-7582. DOI: 10.1016/j.biortech.2011.05.017.

Castello D, Kruse A and Fiori L (2014). Supercritical water gasification of hydrochar. Chemical Engineering Research and Design 92(10):1864-1875. doi.org/10.1016/j.cherd.2014.05.024.

Chuntanapum A and Matsumura Y (2010). Char Formation Mechanism in Supercritical Water Gasification Process: A Study of Model Compounds. Industrial Engineering Chemistry Research, 49(9):4055-4062. DOI:10.1021/ie901346h

Council, NR (1995), Prudent practices in the laboratory: handling and disposal of chemicals,National Academies Press. Washington, D.C.DOI 10.17226/12654.

EPA (2017), "Frequent questions about managing hazardous waste at academic laboratories", United States Environmental Protection Agency,https:/www.epa.gov/hwgenerators/frequent-questions-about-managinghazardous-waste-academic-laboratories

Fedyaeva O and Vostrikov A (2012). Disposal of hazardous organic substances in supercritical water. Russian Journal of Physical Chemistry B, 6(7):844-860. DOI: 10.1134/S1990793112070044.

Fiori L, Valbusa M and Castello D (2012). Supercritical water gasification of biomass for H2 production: process design, Bioresource Technology, 121:139-147. DOI: 10.1016/j.biortech.2012.06.116.

Gasparovic L, Hrablay I, Vojtekova Z. et al. (2011). Kinetic study of pyrolysis of wastewater treatment plant sludge. Chemical Papers, 65: 139. https://doi.org/10.2478/s11696-010-0081-z

Guo L, Cao C and Lu Y (2010). Supercritical water gasification of biomass and organic wastes,InTech Open Access Publisher, Croatia. DOI: 10.5772/9774.

Kratky L and Jirout T. (2015). Effect of rapid batch decompression on hydrolysate quality after hydrothermal pretreatment of wheat straw. Chemical Papers, 69:1563. https://doi.org/10.1515/chempap-2015-0188.

Lee C, Huffman G and Oberacker D (1986). An Overview of Hazardous/Toxic Waste Incineration. $J$ Air Pollution Control Association, 36(8):922-931. 
https://doi.org/10.1080/00022470.1986.10466132.

Louw J, Schwarz CE, Knoetze JH and Burger AJ (2014). Thermodynamic modelling of supercritical water gasification: Investigating the effect of biomass composition to aid in the selection of appropriate feedstock material. Bioresource Technology, 174:11-23. DOI: 10.1016/j.biortech.2014.09.129

Magdeldin M, Kohl T, De Blasio C, Jarvinen M, Won Park S, Giudici R. (2016). The BioSCWG Project: Understanding the Trade-Offs in the Process and Thermal Design of Hydrogen and Synthetic Natural Gas Production, Energies, 9(10):838. doi:10.3390/en9100838

May A, Salvado J, Torras C. and Montane D. (2010). Catalytic gasification of glycerol in supercritical water. Chemical Engineering Journal, 160(2):751-759. https://doi.org/10.1016/j.cej.2010.04.005.

Modell, M. (1977). Reforming of Glucose and Wood at Critical Conditions of Water. Mechanical Engineering, 99(10):108.

Nagasawa Y, Ukai H, Okamoto S, Samoto H, Itoh K, Moriguchi J, Sakuragi S, Ohashi F, Takada S. Kawakami T, Ikeda M2011). Organic Solvent Use in Research Institutions in Japan. Industrial Health, 49(4):421-426. DOI: 10.2486/indhealth.MS1232.

Nanda S, Dalai A, Gokalp I and Kozinski J (2016). Valorization of horse manure through catalytic supercritical water gasification. Waste Management, 52:147158. DOI: 10.1016/j.wasman.2016.03.049.

Schmieder H, Abeln J, Boukis N, Dinjus E, Kuuse A, Kluth M Petrich G, Sadri E, Schacht M (2000). Hydrothermal gasification of biomass and organic wastes. The Journal of Supercritical Fluids, 17(2):145-153.

Solcov O, Topka P, Soukup K, Jiratova K, Vanova H, Kastanek F2014). Solid waste decontamination by thermal desorption and catalytic oxidation methods. Chemical Papers, 68(9): 1279-1282. https://doi.org/10.2478/s11696-013-0455-0

Susanti R, Dianningrum L, Yum T, Kim Tm GwonLee B, Kim J2012). High-yield hydrogen production from glucose by supercritical water gasification without added catalyst. International Journal of Hydrogen Energy, 37(16):11677-11690.

Susanti R, Dianningrum L, Yum T, Kim Tm GwonLee B, Kim J(2014). High-yield hydrogen production by supercritical water gasification of various feedstocks: Alcohols, glucose, glycerol and long-chain alkanes, Chemical Engineering Research and Design, 92(10):1834-1844.

Tushar MSHK, Dutta A and Xu C (2015). Simulation and kinetic modeling of supercritical water gasification of biomass. International Journal of Hydrogen Energy. 40(13): 4481-4493. https://doi.org/10.1016/j.ijhydene.2015.02.033.

van Bennekom J, Venderbosch R, Assink D and Heeres H (2011). Reforming of methanol and glycerol in supercritical water. The Journal of Supercritical Fluids 58(1): 99-113. 10.1016/j.supflu.2011.05.005.

Waddell D (2015). Laboratory Waste Management Guide. Seattle, WA: Local Hazardous Waste Management Program in King County

Withag JA, Smeets JR, Bramer EA and Brem G (2012). System model for gasification of biomass model compounds in supercritical water-a thermodynamic analysis. The Journal of Supercritical Fluids, 61:157166.DOI:10.1016/j.supflu.2011.10.012.

Youssef EA (2011). Supercritical Water Gasification of Biomass \& Biomass Model Compounds. Thesis, the University of Western Ontario. 